\title{
Measuring Knowledge Transfer through Facebook of Higher Education Classroom
}

\author{
Korawan Suebsom
}

\begin{abstract}
This paper presents the outcome of a research that investigates the trend, attitude and perception of students using social media to share knowledge in the classroom. Whilst some people perceived social media as a phenomenon that distracts students from focusing on their studies, others view social media as a technology that can facilitate teaching and learning. This study used mixed method via questionnaire and using focus group to write and share knowledge through social media from 247 students in Nakhon Si Thammarat Rajabhat University of Thailand. The results of the study found that most students used Facebook to discuss and share knowledge in higher education classroom. This study highlights the advantage of social media via Facebook for sharing knowledge in the classroom and used as tools for teaching and learning.
\end{abstract}

Index Terms-Facebook, teaching and learning, attitude, perception.

\section{INTRODUCTION}

Knowledge transfer is often used to exchange the knowledge between among individuals, teams, groups or organization. It is very important because without it, every problem solving approach or operating skill would have to reinvent each time that knowledge is need. Indeed, it may not be overstating the case to say that knowledge transfer is fundamental process of civilization and focus of learning, which is critical all advancement.

Social network is the most important for young people to transfer knowledge and communicate between teachers and friends. Facebook has become the most visited website [1]. What elements influence an individual decision to use social network. This study is an attempt to understand and measure the knowledge and behavior of students based on theory of plan behavior [2]. Especially, finding the attitude and behavior of learners when they intent to use Facebook to transfer or sharing knowledge in the classroom.

Social Network can be Facebook, twitter, MSN, etc.While [3] knowledge transfer is evident when people share their tacit knowledge with one another. Ref. [4] state that knowledge transfer is designed to transform individual knowledge into organizational knowledge. Knowledge transfer is considered as a significant component of knowledge management success [5].

Today, social media technology becomes a part of knowledge transfer and can assist the process of sharing knowledge in the organization. Social media is a dynamic field that can be used to manage knowledge transfer, and social media can also be used as a communication tool where

Manuscript received March 15, 2014; revised May 15, 2014.

Korawan Suebsom is with the Faculty of Education of Nakhon Si Thammarat Rajabhat university, Thailand (e-mail: meena333@live.com). people within the organization will be able to engage in knowledge transfer [6]. Same as in the classroom social media can help students to share knowledge in the classroom because it is easy and convenience to share knowledge from one to another. Today, most universities use the social media as tools for learning and teaching in the classroom. For instance, teachers can send message to his/her students by using Facebook, Line, and Twister. However, the problem which occurs in the classroom is to get the students' attention away from their smart phones, or social media such as Facebook and Line. The other problem in about the disruptive behavior of the students. Therefore, the purpose of this paper is to investigate the trend of social media and technology appropriate for use in the classroom.

This paper attempts to investigate and report on a survey of how students used social media in the classroom and answers questions concerning usage of the social media and types of social media that benefit them in the classroom. The authors hope that the results of this study can be used to improve the courseware and the method for teaching and learning in higher education classroom.

\section{Objectives of This Study}

The purpose of this study is to investigate the trend of using social media as means of sharing knowledge in the classroom. The following objectives are used to guide the study:

1) To investigate the trend of social media for transfer knowledge in higher education.

2) To measure the student's attitude in terms of motivation and satisfaction while using social media for learning and sharing knowledge in higher education.

3) To measure the perception of students in terms of ease of learning when using social media for teaching and learning.

\section{LITERATURE REVIEW}

\section{A. Knowledge Transfer}

Knowledge transfer is important in the educational system since knowledge transfer is the process of transmitting knowledge such as experience and lesson learned from teachers to students. Knowledge transfer involves communication between individuals in the transfer [7]. It can be mediate by the technology in the translation of information. Today, there are many ways of technology to transfer knowledge and to communicate. It can be mediate by the technology in the translation of information.

Today, there are many ways of technology to transfer knowledge and to communicate. Social network is the most important for young people to transfer knowledge and 
communicate between teachers and friends. Facebook has become the most visited website [1]. What elements influence an individual decision to use social network. This study is an attempt to understand and measure the knowledge and behavior of students based on theory of plan behavior [2]. Especially, finding the attitude and behavior of learners when they intent to use Facebook to transfer or sharing knowledge in the classroom. Therefore, this study used the SECI mode as illustrate in Fig. 1.

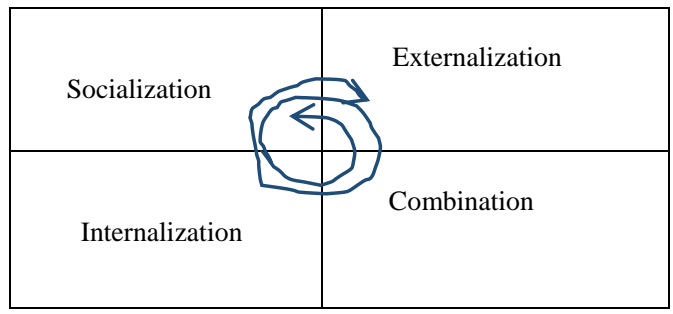

Fig. 1. The SECI model [8].

This study adopted the SECI model developed by [8] that involves four parts, socialization, externalization, combination and internalization. Socialization is to share knowledge via face-to-face such as community of practice (Cops). Therefore, this study looks into knowledge transfer using social media from students' perspective.

In addition, externalization is important for learning and teaching in the classroom. The teacher transfers the knowledge to the students and towards the end of the class, the teacher gives assignments to the students. Whenever the students encounter problems, they will discuss the assignment through social network via Facebook.

The Computer Education Program created a group in Facebook called Computer Family NSTRU. This group has 247 members comprising students of this program. Therefore, the students use this Computer Family NSTRU to discuss about the assignment. If they have problems, they will post the questions to this group and the teachers will answer the question and share knowledge through Facebook. Therefore, knowledge transfer is an exchanged between two or more people. Therefore, Knowledge transfer can be every part of the SECI model.

\section{B. Social Media}

According to [9] , social media is the interaction among people in a virtual environment that facilitate the creation, sharing, and exchange of information and ideas.[10] defined social media as the internet applications build based on Web 2.0 that is focused on the ability for people to collaborate and share information online.

The advancement of the internet technology has brought about extensive use of the social media applications such as Facebook, Myspace, Twitter, WhatsApp, and various other chats, forums and discussion boards. Latest statistics on the usage of Facebook for instance show a world-wide usage of $13.9 \%$. Thailand, with an average Internet penetration of about $30 \%$, has $26.4 \%$ users of Facebook, whilst Malaysia has $46.6 \%$ users of Facebook with $60.7 \%$ Internet penetration (Internet World Stats, 2014). These are way above the Asian average of $6.5 \%$ Facebook users and $27.5 \%$ Internet penetration. This is an indication that social media is becoming pervasive and affecting the lives of many people and is expected to become a necessity in a not too distant future.

\section{Plan Behavior Theory}

Theory of planned behavior (TBP) is a theory about the link between beliefs and behavior. TBP has been shown to be practical in social behavior predicting in many functional areas [5]. This study used the Theory of Planed Behavior based on the three independent variables, which are knowledge perception of using social media, attitude toward using social media and behavioral intention.

\section{Framework of This Study}

The research model of this study adapted from [11] based on the Theory of Planed Behavior. There are three independent variables and one dependent variable as shown in Fig. 2.

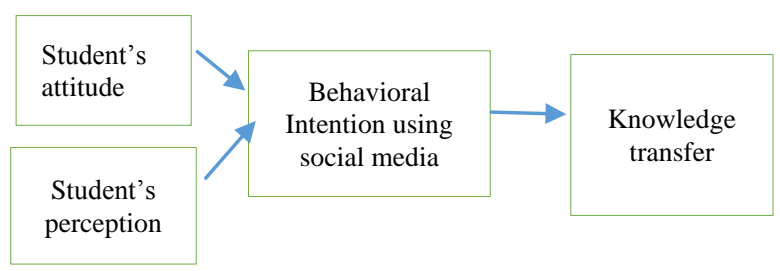

Fig. 2. Framework of this study [11].

\section{E. Variables of This Study}

This study emphasized on three dependent variables which are students' attitude, students' perception, and behavioral intention.

\section{1) Students' attitude}

Attitude means the feeling of each individual person and for this study it refers to the feeling of learners when the instructor transfers knowledge to learners. Many researchers interested in the study of attitude of learners [12] note that knowledge is a precondition of attitude formation. While [13] note that level of knowledge is one of several factors affecting attitudes in children. A significant relationship between knowledge and attitudes concerning the environment has been found in several studies [14] Attitude is important in learning management and there have been many studies on this. According to [15] who studied the attitude toward learner among Spanish university learners and British university learners, found that the learners feel responsible for their own learning, and were motivated by factors other than examinations. For the learners, they normally depend on their teachers for guidance, feedback and motivation. They need the classroom structure to provide discipline and the social environment to give them opportunities for interaction.

\section{2) Students'perception}

Most people assume everyone sees the world the same way. This can be expected because people are not able to compare what they see to what someone else sees. This wildly accepted assumption however can be inaccurate. There is evidence that each person's perception of the world is different only in minor way [16]. The perception can be hearing, vision and smell, each involve different neurons of each individual [17]. However, perception may not be what you think it is. Perception is not just a collection of inputs from our sensory system. But perception is actually message 
constructed using outside input, inner-neuron processes and past, relevant information stored in the brain [16].

\section{3) Behavioral intention}

Behavioural intention is an indication of an individual's readiness to perform a given behaviour. It is assumed to be an immediate antecedent of behaviour [18]. It is based on attitude toward the behaviour, subjective norm, and perceived behavioural control, with each predictor weighted for its importance in relation to the behaviour and population of interest. Therefore, this study adapted the behavioural intention as the activities and frequency of using social media.

\section{MethodolOGY}

The method of this study were both quantitative and qualitative design was used in this study, the instrument was used based on theory of Planed Behaviour and divided into three parts. The first part is independent variable which consists of student's attitude and student's perception. The second part is behaviour intention which includes the activities and frequency of using social media. The third part is about knowledge transfer. These variables were subjected to reliability tests and found to be reliable as illustrated by their Cronbach alpha values of between .700 and .800 respectively.

\section{A. The Instrument}

The instrument was developed based on the knowledge transfer and experience of the environmental education plus extensive literature search on the subject. The study selected a subject called knowledge management in education (CIT 4123516). The subject namely Computer Learning Management for Secondary Education, which includes of knowledge transfer and the channel of sharing knowledge via Facebook, Line, Twister, Linked In, blog etc. The instrument consists of five parts; personal data, student's attitude, student's perception, behavioral intention and knowledge transfer. Therefore, the reasons of choosing this subject because the course syllabus of this subject is describe about the tools and technique of teaching and the students can use the many ways of sharing knowledge such as Facebook, Line etc. The instrument was justified by the two experts. One expert is a Professor in Information Technology and the other is a lecturer who is an expert in psychology.

\section{B. Population}

The sample population are the students from faculty of education. The faculty of education included 10 major courseware which are Thai language, social education, physical education, English language, computer education, science education, psychology education, mathematical education, physic education and early childhood education. This study selected the sampling population from 247 students from computer education program because most students always used social media in the classroom and at home. Therefore, the sample size of 200 was determined for this study.

\section{Data Collection}

The study used survey questionnaires sent online and by email to all participants. The questionnaire included survey questionnaire and structured as well as opened-ended questions. Selected participants completed the questionnaire and returned by using Facebook Chat, email and Line.

\section{DATA ANALYSIS}

Various techniques were used to analyze the data including descriptive statistics, reliability analysis and also factor analysis. Factor analysis was carried out to assess construct validity, whereas regression analysis was used to analyze the data. All respondents were undergraduate students, in term of gender, 48 (24\%) were males and the remaining $152(76 \%)$ were females. The respondents age between 17-19 years old. Table I shows the frequency of using social media.

TABLE I: THE FREQUENCY OF USING SOCIAL MEDIA

\begin{tabular}{|c|c|c|}
\hline Using social media & frequency & Percentage \\
\hline Always & 72 & 35.6 \\
\hline Usually & 29 & 14.4 \\
\hline Often & 23 & 11.4 \\
\hline Occasionally & 40 & 19.8 \\
\hline Seldom & 36 & 19.8 \\
\hline
\end{tabular}

Table I shows the frequency of using social media and found that almost all respondents used the social media with slightly less than $20 \%$ of respondents indicated that they seldom use the social media.

TABLE II: TYPES OF SOCIAL MEDIA

\begin{tabular}{|c|c|c|}
\hline $\begin{array}{c}\text { Types of social } \\
\text { media }\end{array}$ & $\begin{array}{c}\text { Frequency } \\
\text { of learning to use }\end{array}$ & $\begin{array}{c}\text { Percentage } \\
(100 \%)\end{array}$ \\
\hline Facebook & 142 & 70.3 \\
\hline Twister & 9 & 4.5 \\
\hline LinkedIn & 13 & 6.4 \\
\hline What App & 36 & 18.8 \\
\hline & 200 & 100 \\
\hline
\end{tabular}

Table II shows the four types of social media used as tools for sharing knowledge in this study. Not surprisingly, 70.3\% of respondents indicated that they use Facebook, with WhatsApp falling far behind at $18.8 \%$. Therefore, this study can report that most students used Facebook as a tool for discussing and transferring knowledge.

TABLE III: KNOWLEDGE TRANSFER VIA SOCIAL MEDIA

\begin{tabular}{|c|c|c|}
\hline Knowledge transfer & frequency & Percentage \\
\hline Always & 122 & 60.4 \\
\hline Usually & 37 & 18.3 \\
\hline Often & 36 & 17.8 \\
\hline Occasionally & 3 & 1.5 \\
\hline Seldom & 4 & 2 \\
\hline
\end{tabular}

Table III shows the frequency of using social media to share knowledge between teachers and students, or between students and friends. Majority of respondents (60.4\%) indicated they always used the social media for knowledge transfer whilst only $2 \%$ indicated they seldom use the social media to share knowledge.

TABLE IV: PURPOSE OF USING THE CHAT FACILITY

\begin{tabular}{|c|c|c|}
\hline Purpose of chatting & Frequency & Percentage \\
\hline General chat & 18 & 8.9 \\
\hline Discuss homework & 115 & 56 \\
\hline Private chat & 7 & 3.5 \\
\hline Chat with group & 60 & 29.7 \\
\hline
\end{tabular}

Table IV shows the purpose of using the chat facility. The 
results indicate majority of respondents $(56 \%)$ used the chat facility to discuss about their homework.

TABLE V: The Total Time USING Social MEDIA PER DAY

\begin{tabular}{|c|c|c|}
\hline $\begin{array}{c}\text { Total time using social media } \\
\text { /day }\end{array}$ & Frequency & percent \\
\hline 2 hours & 23 & 11.4 \\
\hline 3 hours & 51 & 25.2 \\
\hline 4 hours & 29 & 14.4 \\
\hline 5 hours & 28 & 13.9 \\
\hline$>5$ hours & 69 & 34.2 \\
\hline
\end{tabular}

Table V shows the total time using social media per day. The results show that students spend longer hours per day on social media with $34.2 \%$ of respondents indicated they spent at least 5 hours.

To meet the objectives of the study the following hypotheses have been formulated.

Hypothesis 1: Using the social media have influenced knowledge transfer attitude in higher education.

\begin{tabular}{c|c|c|c|c|c}
\multicolumn{7}{c}{ TABLE VI: MODEL SUMMARY OF RESULTS } \\
\hline Model & Predictors & $\mathrm{R}$ & $\mathrm{R} 2$ & $\mathrm{~F}$ & Sig.F \\
\hline 1 & $\begin{array}{c}\text { Social } \\
\text { media }\end{array}$ & 0.695 & 0.483 & 185.05 & .000 \\
\hline
\end{tabular}

Table VI illustrate the results from Table VI have shown that the simple regression coefficient $(\boldsymbol{R})$ of social media and knowledge transfer attitude is .695 and the $\boldsymbol{R}^{2}$ is .483 . The value of $\mathrm{F}$ is $185.05(p<.05)$.

Hypothesis 1 examined the relationship between using social media and knowledge transfer attitude. Linear regression was analysis the data. The result found that there is significantly related between using the social media have influence knowledge transfer attitude in higher education at the $p<.05$. Accordingly, this hypothesis is supported.

Hypothesis 2: Using social media can motivate knowledge transfer in the classroom

\begin{tabular}{|c|c|c|c|c|c|}
\hline Model & Predictors & $\mathrm{R}$ & $\mathrm{R} 2$ & $\mathrm{~F}$ & Sig.F \\
\hline 1 & $\begin{array}{l}\text { Social } \\
\text { media }\end{array}$ & 0.237 & .056 & 11.815 & .001 \\
\hline
\end{tabular}

The results from Table VII have shown that the simple regression coefficient $(\boldsymbol{R})$ of social media and motivate knowledge transfer is .237 and the $\boldsymbol{R}^{2}$ is .056. The value of F is $11.815(p<.01)$. Therefore, this study is significantly related at the level of $p<.01$.

Hypothesis 3: the satisfactory of using social media is significantly related to learning outcome

TABLE VIII: MODEL SUMMARY OF RESULTS
\begin{tabular}{|c|c|c|c|c|c|}
\hline Model & Predictors & R & R2 & F & Sig.F \\
\hline 1 & Satusfactory & 0.30 & 0.09 & 19.581 & .000 \\
\hline
\end{tabular}

The results from Table VIII have shown that the simple regression coefficient $(\boldsymbol{R})$ of satisfactory of using social media and learning outcome is .300 and the $\boldsymbol{R}^{2}$ is .090 . The value of $F$ is 19.581 ( $p<.05)$. Therefore, this study is significantly related at the level of $p<.05$. Therefore, the students are satisfactory of using social media are significantly related to learning outcomes at $p<0.05$.

Hypothesis 4: the social media is significantly related learner's perception

Table IX illustrates the model summary of results between social media and learners' perception. The results from Table
IX have shown that the simple regression coefficient $(\boldsymbol{R})$ of social media is .264 and the $\boldsymbol{R}^{2}$ is .070 . The value of $\mathrm{F}$ is 14.812 ( $p<.05)$. Hypothesis 4 examined the relationship between social media and learner's perception. Therefore, the social media is significantly related to learner's perception at the $p<.05$. Accordingly, hypothesis 4 which state that the social media that the students use in the classroom can help learner to perceived knowledge and sharing knowledge with teachers and friends. For the qualitative analysis was used content analysis to support the quantitative analysis because this study reported that using Facebook to transfer knowledge can improve learning outcome in the classroom.

TABLE IX: MODEL SUMMARY OF RESULTS

\begin{tabular}{|l|l|l|l|l|l|}
\hline Model & Predictors & $\mathrm{R}$ & $\mathrm{R} 2$ & $\mathrm{~F}$ & Sig.F \\
\hline 1 & Social media & 0.264 & .070 & 14.812 & .000 \\
\hline
\end{tabular}

\section{DISCUSSION}

The results of this study reported that all most students used the social media and the popular social media is Facebook. The students like to share knowledge or discuss the assignment through Facebook. The purpose of chatting are discussing homework and the students used chat in group namely Computer Family Nakhon Si Thammarat and the total of chatting are more than 5 hours. The study was analyzed hypotheses and found that 1) using the social media have influenced knowledge transfer attitude in higher education. This hypothesis support by [19] reported that the social network had influence the knowledge transfer attitude in organization. While 2) using social media can motivate knowledge transfer in the classroom. Since the social media can enhance the students which intend in the classroom. This hypothesis argue with [20] which Students are more motivated to use the tool when social media as tool to reflect other students' solutions and give feedback. 3) The students had enjoy and satisfactory to learn and 4) using social media for sharing knowledge and the social media is significantly related learner's perception because the social media can increase the learning outcome too. These hypotheses argue with [20] state that social media enhance the satisfaction and increase the learning outcomes of students.

\section{CONCLUSION}

The study emphasized on knowledge transfer through social media for higher education classroom based on the theory of Planned Behavior. The study focused on the trend of social media which students have been using today and relate to knowledge transfer, learner's perception when using social media as tools for learning and teaching in the classroom. This study found that the social media have influenced knowledge transfer between teachers and the students. Furthermore, social media can act as a motivator to encourage knowledge transfer in the classroom. This means the social media can motivate the students for sharing knowledge in the classroom. This study also suggests the use of social media can increase students' satisfaction and perception towards ease of learning. In summary, social media is important for teaching and learning in the classroom today. Teachers and students will embrace the social media in 
classrooms and it will be good to develop more online courseware programs. Future research should compare the different social media as tools for effective teaching and learning.

\section{REFERENCES}

[1] A. Wilhelm. (Feb. 22, 2010). Twitter statistics: The full picture. [Online]. Available: http://thenextweb.com/socialmedia/2010/02/22 witter-statistics-full-picture/

[2] I. Ajzen and M. Fishbein, Understanding Attitudes and Predicting Social Behavior, Englewood Cliffs: Prentice-Hall, Inc., 1980.

[3] D. Adamovic, A. Potgieter, and M. Mearns, "Knowledge transfer through social media: Investigating trends and technologies in a global marketing and advertising research company," Journal of Information Management, vol. 14, no. 1, pp. 514, 2012.

[4] N. J. Foss, K. Husted, and S. Michailova, "Governing knowledge sharing in organizations: levels of analysis, governance mechanisms, and research directions," Journal of Management Studies, vol. 47, pp. 455-82, 2010.

[5] E. Aliakbar, M. B. R. Yusoff, and N. N. H. Mahmood, "Determinants of Knowledge transfer Behavior," in Proc. 2012 International Conference on Economics, Business and Marketing Management IPEDR, Singapore: IACSIT Press, 2012,

[6] M. P. Jones. (2009). Collaborative Knowledge Management, Social Networks, and Organizational Learning. [Online]. Available: http://human-factors.arc.nasa.gov/publications/collab_know_paper.pd $\mathrm{f}$

[7] V. Albino, A. C. Garavelli, and M. Gorgoglione, "Organization and technology in knowledge transfer," Benchmarking: An International Journal, vol. 11, no. 6, pp. 584-600, 2004.

[8] I. Nonaka and H. Takechi, The Knowledge Creating Company, New York: Oxford University Press.

[9] Wikipidia. (2012). [Online]. Available: http://en.wikipedia.org/wiki/Knowledge_sharing

[10] A. M. Kaplan and M. Haenlein, "Users of the world, unite! The challenges and opportunities of Social Media," Business Horizons, vol. 53, no. 1, pp. 59-68. doi:10.1016/j.bushor.2009.09.003, 2010.

[11] A. Pamela and D. Bryant, "Faculty perceptions of pedagogical benefits of web 2.0 technologies and variables related to adoption," Information System, vol. 13, no. 1, pp. 258-263, 2012.

[12] F. G. Kaiser, S. Woelfing, and U. Fuhrer, "Environmental attitude and ecological behavior," Journal of Environmental Psychology, pp. 191-192, 1999.
[13] S. Kellert, "Attitudes toward animals: Age-related development among children," Journal of Environmental Education, 1984.

[14] K. Suebsom, "A study of Learners' behavior toward using facebook in the classroom of Nakhon Si Thammarat Rajabhat University of Thailand," presneted at 2013 e-CASE \& e-Tech International Conference, April 3 - April 5, 2013.

[15] R. Breeze. (2002). Attitudes towards Learning Autonomy among Spanish University Students. [Online]. Available: http://www.attantisjournal.org/papers/24-1/breeze.pdf.

[16] R. Mosher. (1998). Model for Perception. [Online]. Available: http://serendip.brynmawr.edu/bb/neuro/neuro98/202s98-paper1/Mosh er.htmlNational Education Commission.

[17] H. J. Little, "The contribution of electrophysiology to knowledge of the acute and chronic effects of ethanol," Pharmacol, 1999.

[18] I. Ajzen, "Perceived Behavioral control, self-efficacy, locus of control, and the theory of planned behavior," Journal of Applied Social Psychology, vol. 32, pp. 665-683, 2002.

[19] S. W. Chow and L. S. Chan, "Social network, social trust and shared goals in organizational knowledge transfer," Journal of Information and Management., vol. 4, pp. 458-465.

[20] J. Konert, S. Göbel, K. Richter, and R. Bruder, "Knowledge transfer in the classroom A social network approach for diagnostic assessment and learning together," presented at the 11th IEEE International Conference on Advanced, 2010,

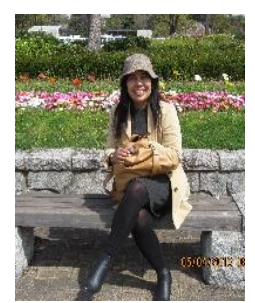

Korawan Suebsom was born in March, 1969 in Phattalung province, Thailand. She graduated bachelor degree in computer education from Rajabhat Songkhla University. She started her career as a lecturer at Nakhon Sri thammarat Rajabhat University in 1999. In 2006, she received her master of information technology from Assumption University. She received her doctoral of philosophy in information technology in 2009 from Universiti Utara Malaysia. She has presented several papers internationally as a result of research that have been made. In Asia -Pacific Collaborative Journal Volume 6, Number 1, 2010: Measuring Knowledge Transfer As Learning Outcomes Using Electronic Media. The last proceeding paper conference at 2013 e-CASE and e-Technology in Kitakhyshu, Japan.

Currently, she is the head of computer education program in the Faculty of Education of Nakhon Si Thammarat Rajabhat University. 